\title{
Blocked isocyanates as alternative curing agents for epoxy-polyurethane resins based on modified vegetable oils
}

\author{
A. Sienkiewicz, P. Czub* \\ Department of Chemistry and Technology of Polymers, Faculty of Chemical Engineering and Technology, Cracow \\ University of Technology, Warszawska Str. 24, Cracow, Poland
}

Received 14 December 2018; accepted in revised form 25 February 2019

\begin{abstract}
Presented research shows the results of a study on the synthesis and mechanical properties of materials obtained by crosslinking polyaddition bio-products with blocked isocyanate based on toluene diisocyanate (TDI) as curing agent. Bio-resins, polyaddition product of epoxidized soybean oil and bisphenol A or hydroxylated soybean oil and low molecular weight epoxy resin, were synthesized via modern and pro-ecological modification of the synthesis of epoxies, namely, the epoxy fusion process. The obtained polyaddition product contains free epoxy and hydroxyl groups, which are suitable for the curing purposes. Material cured with Desmodur BL 1265/MPA/X in the presence of organometallic or amine catalyst (respectively: Dabco T9 and Dabco 33-LV) is characterized by mechanical properties better than the composition crosslinked without the catalyst. Additionally, there is a possibility of the synthesis of two-layer materials by chemical bonding of two different compositions via the previously unused oxirane groups of the cured ESBO_BPA or SMEG_EPR products.
\end{abstract}

Keywords: biopolymers, soybean oil, epoxy resin, epoxy fusion process, blocked isocyanates

\section{Introduction}

The big challenge for modern chemical research is the necessity to develop new technologies or upgrade the old ones by the application of new sources of raw materials, which would become an alternative to petroleum-derived feedstocks. Invariably, the primary goal is to care for the natural environment. Hence, in the synthesis and modification of plastic materials such as: poly(hydroxyalcanoates) [1], polyesteramides [2], polyetheramides [3], alkyds [4] and epoxy resins, there is a wide interest in the use of raw materials of natural origin. Vegetable oils, which are biodegradable, renewable, non-toxic, environmentally benign and easily modified [5], are used in the technology of epoxies as: additives, flexibilizers $[6,7]$, and diluents [8], decreasing viscosity of epoxy resins or bio-alternatives for raw petrochemical materials in the process of their synthesis [9-11].
We have been working on the application of a novel method of the synthesis of epoxy materials using modified vegetable oil. This new and interesting reaction is based on a conventional method of the synthesis of high-molecular-weight $(1500-10000 \mathrm{~g} / \mathrm{mol})$ epoxy resins in the epoxy fusion process involving low- and average-molecular-weight epoxies and bisphenols [12] (Figure 1). The method, which meets the requirements of 'green chemistry', eliminates the necessity for the application of solvents, strong acids and alkali, which are harmful to the environment [13]. The process is simple and gives an opportunity to obtain a product with pre-determined properties and molecular weight. The introduction of vegetable oils results in obtaining a product with characteristics (e.g. lower viscosity [14] and higher resilience) better applicable than by the conventional method using petrochemical raw materials. Obtained bio-based 
epoxy material contains free epoxy and hydroxyl groups, which are suitable for the curing purposes. It is possible to crosslink products of the epoxy fusion process with, e.g. diisocyanates, obtaining novel epoxy-polyurethane materials characterized by the properties resulting from the choice of the curing method $[13,15,16]$. Facing the present ecological requirements, we obtained materials using polyisocyanates such as: hexamethylene diisocyanate (HDI), diphenylmethane-diiscoyanate (MDI) and tolene-diisocyanate (TDI) [15], and also blocked isocyanates (Desmocap 11, Desmocap 12, Desmodur BL1265, Desmodur BL 3272 MPA, Desmodur BL 3175 SN, Desmodur BL $4265 \mathrm{SN}$ and Desmodur PL 340 $\mathrm{BA} / \mathrm{SN})$.

One of the most important methods of the environmental protection is the replacement of toxic chemicals with compounds that have less harmful effects or reducing the toxicity of the compounds that are difficult to completely eliminate from the mass production and use. Polyurethanes are an extremely important group of polymeric materials used on a mass scale. Isocyanates, which are commonly used in the synthesis of polyurethanes, are very harmful raw materials and so far they are difficult to completely eliminate or replace. However, their harmfulness can be significantly reduced by temporarily blocking of the isocyanate groups (for the duration of storage and application) and consistently conducting the polyurethane synthesis process under the conditions in which -NCO groups are unblocked. Recently, blocked isocyanates are getting more attention as new generation curing agents due to their more environmentally friendly character $[17,18]$. With this type of hardeners, the reactive group $-\mathrm{NCO}$ is blocked with e.g. $\varepsilon-$ caprolactam, methylethylketoxime, pyrazole and diethyl malonate [19] of the general formula H-B. The decomposition reaction of the blocked isocyanate with the release of the free isocyanate group takes place at an elevated, so-called unblocking temperature, characteristic for a given system ( $\mathrm{R}-\mathrm{NH}-\mathrm{CO}-\mathrm{B})$. Below this temperature, the isocyanate is in a blocked form, which significantly influences its reactivity and toxicity. As the temperature rises, a released, highly reactive -NCO group reacts with the appropriate substrate containing nucleophilic groups to form the final product.

The aim of the study presented in this manuscript was research on the application of various blocked isocyanates based on HDI and TDI, which are active under propitious conditions, for the curing of epoxy fusion products from modified soybean oil.

\section{Material and methods}

Materials. In the performed experiments epoxidized soybean oil (ESBO, Ergoplast EG, Boryszew, EV=

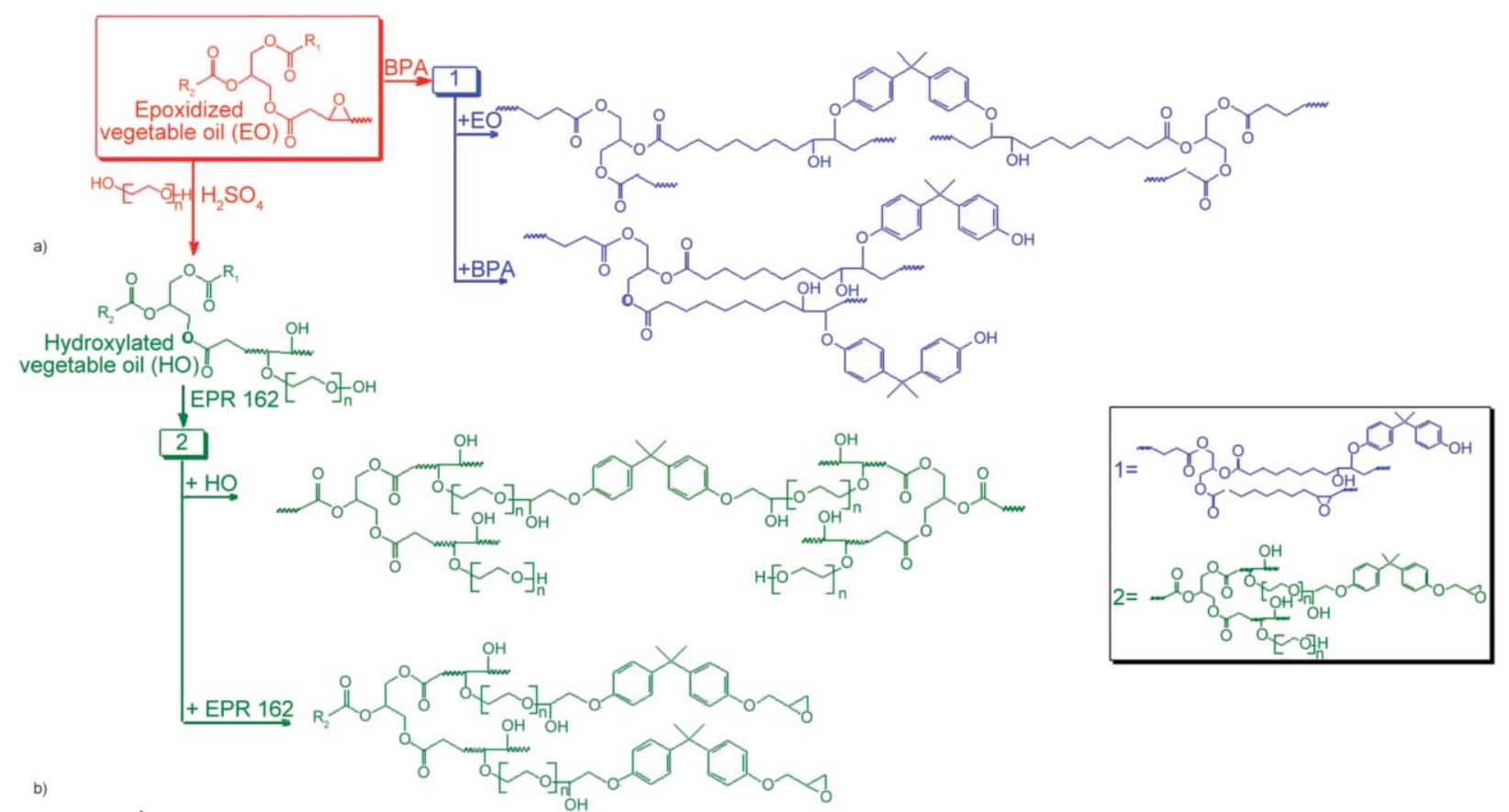

Figure 1. The synthesis of high-molecular-weight epoxy resins based on modified vegetable oil: (a) epoxidized or (b) hydroxylated soybean oil. 
$0.363 \mathrm{~mol} / 100 \mathrm{~g}$; with an average 3.52 epoxide groups and 0.03 hydroxyl groups per 1 oil molecule) was used.

\subsection{Hydroxylation of ESBO}

In the first step oxirane rings in ESBO were open with the use of ethylene glycol (POCh S.A., pure). The reaction was carried out for $5 \mathrm{~h}$ at $110^{\circ} \mathrm{C}$ and with the molar ratio of glycol to epoxy groups of 1.05. Additionally, 0.013 moles of sulfuric(VI) acid per 1 mole of epoxy groups in the epoxidized oil were used. Next, the reaction mixture was cooled and calcium carbonate was added to neutralize sulfuric acid. In the subsequent step, the organic phase was washed several times with hot distilled water and subjected to distillation under reduced pressure to remove, residue of water and unreacted glycol from the mixture.

\subsection{Epoxy fusion process}

Modified vegetable oil (epoxidized or hydroxylated soybean oil, SMEG), bisphenol A (BPA, GE Cartagenie, $99.93 \%$ ) or low molecular weight epoxy resin (EPR 0162, Hexion Specialty Chemicals, Inc., USA, $E V=0.584 \mathrm{~mol} / 100 \mathrm{~g}$ ) respectively, and $\mathrm{LiCl}$ (Merck, pure; in amount of $0.002 \mathrm{~mol}$ per $1 \mathrm{~mol}$ of $-\mathrm{OH}$ groups) had been involved in the fusion reactions. Process was carried out in nitrogen atmosphere. The reaction mixture of modified soybean oil and BPA or EPR 162 was homogenized, followed by adding $\mathrm{LiCl}$ and raising to the desired temperature of $160^{\circ} \mathrm{C}$. The duration of the process was established experimentally by monitoring the epoxy value of reacting mixture [20]. The process was carried out until the assumed content of epoxy groups in the final product was reached. We obtained two polyaddition products: ESBO_BPA (via the reaction of epoxidized soybean oil and bisphenol A) and SMEG_EPR (throughout the fusion process of hydroxylated soybean oil and low molecular weight epoxy resin).

\subsection{Curing}

Curing process was carried out using the reaction of hydroxyl groups of polyaddition products (ESBO_BPA or SMEG_EPR) and -NCO groups of applied hardener. The amounts of substrates were selected with the respect of Equation (1):

$$
m_{\text {hardener }}=\frac{H V \cdot 100 \cdot 42}{\% \mathrm{NCO} \cdot 561}
$$

where: $m_{\text {hardener }}-$ mass of the hardener, which is necessary to crosslink $100 \mathrm{~g}$ of the polyaddition product, $H V$ - hydroxyl value of polyaddition product and $\% \mathrm{NCO}$ - the content of free isocyanate groups in the hardener.

Crosslinking of synthesized polyaddition product was carried out with the following reagents (Table 1).

A homogeneous mixture consisting of a suitable polyaddition product, hardener, deaerator (and catalyst) was poured in metal cuvettes. Then the compositions were heated at $40^{\circ} \mathrm{C}$ in a vacuum oven in order to get rid of any air introduced during the preparation process. Finally, the materials were cured at $140^{\circ} \mathrm{C}$ [21] for about $2 \mathrm{~h}$.

\subsection{Two-layer materials were obtained on the course of a two-stage process}

First, according to the above described procedure, materials based on (1) hydroxylated soybean oil and polyaddition products: (2) ESBO_BPA and (3) SMEG_EPR were synthesized using D'Dur 1265 as a curing agent. Then, on the cured material: (1) SMEG+D'Dur 1265, (2) ESBO_BPA+D'Dur 1265 or (3) SMEG_EPR+D'Dur1265 a homogenous composition based on commercial epoxy resin Epidian 6 (Organica-Sarzyna, $E V=0.584 \mathrm{~mol} / 100 \mathrm{~g}$ ) and the hardener Aradur 46 (Huntsman Advanced Materials $\mathrm{GmbH}$, Germany, isophorone diamine with amine value $320 \mathrm{mg} \mathrm{KOH} / \mathrm{g}$ and 95 equivalent active protons; Epidian 6 and Aradur 46 were mixed stoichiometricly with the respect of the content of oxirane groups of the epoxy resin and active protons of hardener) were poured into metal cuvettes and the material was cured for $24 \mathrm{~h}$ at room temperature.

\subsection{Epoxy and hydroxyl values}

The content of the epoxy and hydroxyl groups in the analyzed products were evaluated by titration methods. Whereas, the epoxy value $(E V)$ was evaluated according to PN-87/C-89085/13 standard: the samples were dissolved in $\mathrm{HCl} / 1$,4-dioxane solution $(1.9 \mathrm{~mol} / \mathrm{l})$ and titrated by $\mathrm{NaOH} / \mathrm{methanol}(0.2 \mathrm{~mol} / \mathrm{l})$ in a presence of cresol red as indicator to the visual change of tint to purple. This titration method is based on the quantitative reaction of hydrogen chloride with epoxy groups in an environment of 1,4-dioxane at room temperature, followed by the titration of excess hydrogen chloride with standard alcoholic solution of 


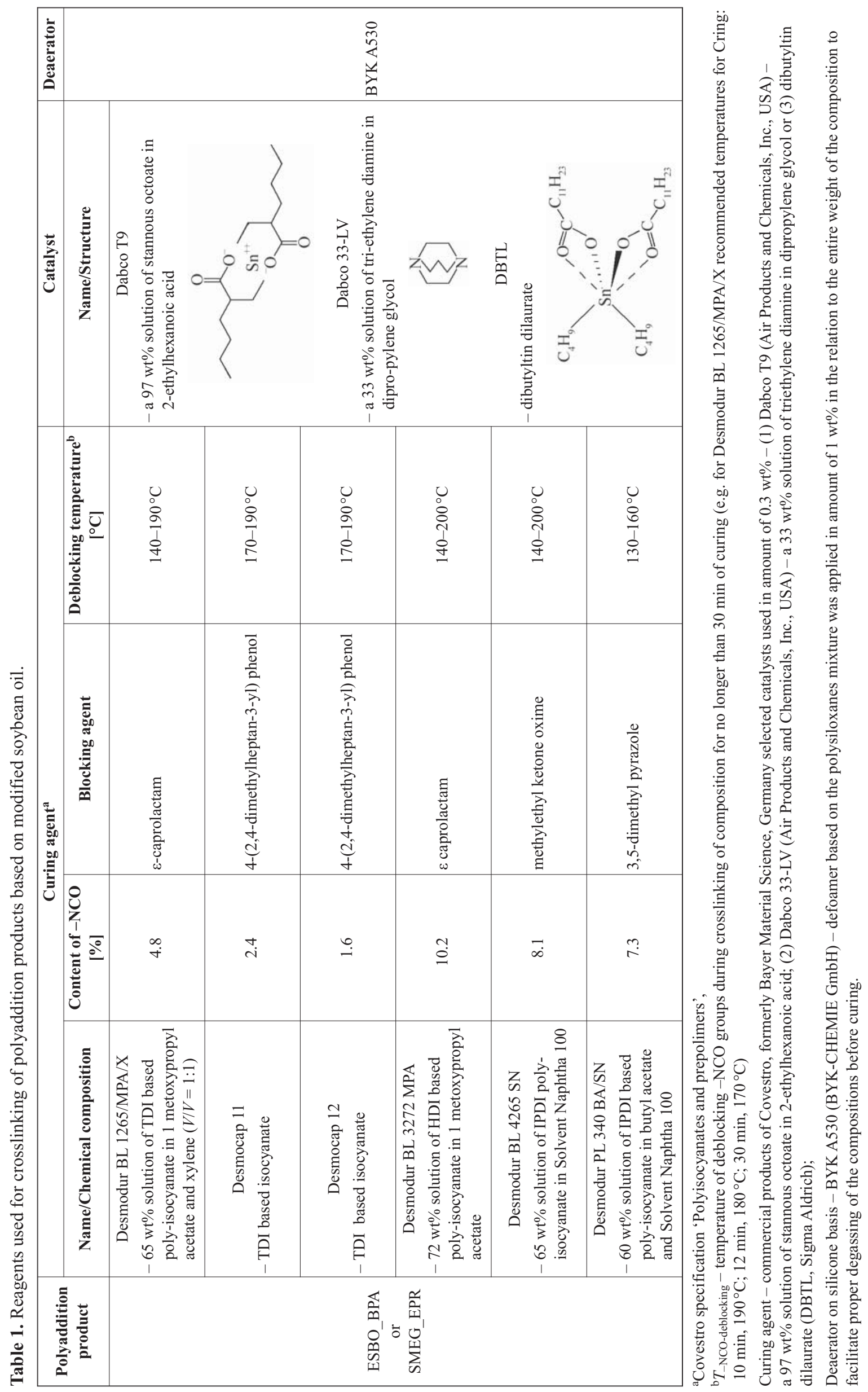


sodium hydroxide. Cresol red, used as an indicator, changes its color upon the change of $\mathrm{pH}(\mathrm{pH}=7.2$ yellow to 8.8 - red) of the analyzed solution. In order to define the hydroxyl value $(H V)$, samples of analyzed products were dissolved in the solution of catalyst [4(dimethylamine)pyridine in DMF $-0.1 \mathrm{~mol} / \mathrm{l}$ ] and acetic anhydride in DMF (2.4 mol/l), respectively, followed by an intensive stirring for 15 minutes and titration with $\mathrm{KOH}$ aqueous solution $(1 \mathrm{~mol} / \mathrm{l})$ in the presence of thymolphthalein until the tint changed from colorless to blue. This titration method involves acetylation of hydroxyl groups with acetic anhydride, followed by the decomposition of the excess of acetic anhydride to acetic acid with water and finally titration by the potassium hydroxide solution. Thymolphthalein, used as indicator, changes its color depending on the $\mathrm{pH}$ of the solution $(\mathrm{pH}<9.3-$ colorless, $\mathrm{pH}>10.5$ - blue).

\subsection{Gel permeation chromatography}

The number-average molecular weight $\left(\bar{M}_{\mathrm{n}}\right)$, weightaverage molecular weight $\left(\bar{M}_{\mathrm{W}}\right)$, and polydispersity (PDI) of the obtained products were determined by Knauer gel-permeation chromatography with two PL-gel columns $(300 \times 7.5 \mathrm{~mm})$ with grain size $3 \mu \mathrm{m}$ and MIXED-E pores, and a refractive index detector. The equipment was calibrated using standard polystyrene samples in the molecular weight range of 410 to $20500 \mathrm{~g} / \mathrm{mol}$. The analyses were performed at $25^{\circ} \mathrm{C}$ and tetrahydrofuran, dried over metallic sodium, distilled and stabilized with BHT (2,6-bis(1,1dimethylethyl)-4-methylphenol), was used as an as eluent (with eluent flow $0.8 \mathrm{ml} / \mathrm{min}$ ).

\subsection{Mechanical properties}

\subsubsection{Single-layer materials}

The mechanical properties of the prepared composition were tested according to the standard PN-EN ISO 527-2 on samples in the forms of paddles $2 \times 5 \mathrm{~mm}$ and measuring length $25 \mathrm{~mm}$. The tensile strength, elongation at break, modulus of elasticity were tested on the Zwick 1445 apparatus equipped with an extensometer. Hardness in Shore's A scale was tested according to PN-EN ISO 868:2005 standard with the use of the InSize apparatus. The deflated indenter of the device was pressed against the material with its base at least $10 \mathrm{~mm}$ from the edge of the sample.

\subsubsection{Two-layer materials}

The obtained material was cut according to the standard PN-EN 205:2016-09 into strips 20 $\pm 0.2 \mathrm{~mm}$ wide (whereby a $7.5 \mathrm{~mm}$ wide strip was cut from the outer edge of each two-layer sheet of material) and $150 \pm 5 \mathrm{~mm}$ length. On each strip $2.5 \pm 0.5 \mathrm{~mm}$ wide cuts (completely cutting the intersection weld, however as little as possible of the second layer) were made in such a way that a tab with a length of $10.0 \pm 0.2 \mathrm{~mm}$ was formed in the middle of the sample of two-layer material. These cuts were used to separate the individual layers. Prepared samples were stretched on the Zwick 1445 apparatus to determine the shear strength when stretching overlapping joints. The ends of the samples were clamped in the jaws of a testing machine over a length of $50 \mathrm{~mm}$. The test was made at a feed speed of $6 \mathrm{~mm} / \mathrm{min}$.

\subsection{Morphological analysis}

Morphological analysis of the obtained materials was made using the JEOL JSM-6010LA Scanning Electron Microscope (Tokyo, Japan) at $5 \mathrm{kV}$ acceleration. SEM micrographs were recorded for the impact fracture surface of the cured single-layer compositions or post-sheer stress surface of samples of two-layer materials. The approximate dimensions of samples were $2 \times 10 \mathrm{~mm}$. The surface of samples was coated with a thin film of gold.

\subsection{Thermal properties}

The thermal stability of the obtained epoxy-polyurethane compositions was determined by thermogravimetric analysis using a Netzsch TG 209 apparatus. Samples with a mass of approx. $5 \mathrm{mg}$ were heated under argon at a rate of $10^{\circ} \mathrm{C} / \mathrm{min}$ in the temperature range from 30 to $600^{\circ} \mathrm{C}$.

\section{Results and discussion}

We obtained high molecular weight epoxy resin using epoxidized and hydroxylated soybean oil in the epoxy fusion process with bisphenol A (BPA) or subsequently with low molecular weight epoxy resin (EPR 162). As a result of the polyaddition reactions, products were in the form of viscous liquids. Based on GPC analysis the ESBO BPA product contains oligomers of weight-average molecular weight, both 1300 and $11000 \mathrm{~g} / \mathrm{mol}$. Compared to ESBO_BPA, the 
Table 2. Physicochemical properties of polyaddition products of modified soybean oil with BPA and with a low molecular weight epoxy resin based on bisphenol A.

\begin{tabular}{|l|c|c|c|c|c|}
\hline Polyaddition product & $\begin{array}{c}\overline{\boldsymbol{M}}_{\mathbf{n}} \\
{[\mathbf{g} / \mathbf{m o l}]}\end{array}$ & $\begin{array}{c}\overline{\boldsymbol{M}}_{\mathbf{w}} \\
{[\mathbf{g} / \mathbf{m o l}]}\end{array}$ & PDI & $\begin{array}{c}\boldsymbol{E V}^{\mathbf{a}} \\
{[\mathbf{m o l} / \mathbf{1 0 0 g}]}\end{array}$ & $\begin{array}{c}\boldsymbol{H}^{\mathbf{b}} \\
{[\mathbf{m g} \mathbf{K O H} / \mathbf{g}]}\end{array}$ \\
\hline ESBO_BPA & 1668 & 3981 & 2.39 & 0.118 & 144 \\
\hline SMEG_EPR & 2267 & 19320 & 8.52 & 0.113 & 160 \\
\hline
\end{tabular}

aepoxy value $(E V)$

'hydroxyl value $(H V)$ - both determined by the titration method (see part 2.5 in the section 'Materials and methods')

SMEG_EPR polyaddition product contains oligomers of weight-average molecular weight both 5300 and $65000 \mathrm{~g} / \mathrm{mol}$. Additionally, polyaddition products contained both hydroxyl and epoxide groups, which can be used in the process of their crosslinking (Table 2). Moreover, the course of the polyaddition process using modified soybean oil and the structure of obtained polyaddition products were determined (by means of MALDI-TOF spectrometry and NMR spectroscopy) and described in our previous research papers $[16,26]$. The final polyaddition product ESBO_BPA or SMEG_EPR, obtained by the epoxy fusion process conducted in bulk, consists of macromolecules with various structure. Additionally, it has been found that products with linear, rather than branched, structure are more likely to be formed. Within the first section of this manuscript we would like to present the synthesis and the properties of materials obtained using crosslinking throughout only
$-\mathrm{OH}$ groups (Figure 2). The reaction between $-\mathrm{OH}$ and-NCO results in the formation of urethane or allophanate bond, wherein allophanate formation can occur under conditions of elevated temperature and the presence of excess isocyanate in the immediate vicinity of the urethane linkage [27]. In the obtained polyaddition product, above-mentioned hydroxyl groups are dominant next to oxirane groups. Both the consumption of $-\mathrm{OH}$ groups and the crosslinking of polyaddition products using diisocyanates allow obtaining interesting epoxy-polyurethane bio-materials. Moreover, it is necessary to mention that for curing purposes more environmentally friendly, blocked isocyanates had been selected. Their activation is possible under moderate conditions of a crosslinking process. That is why, in the next step numerous curing tests were carried out using provided in Table 1 blocked isocyanates. During the preparation of above compositions, it was observed that the application of

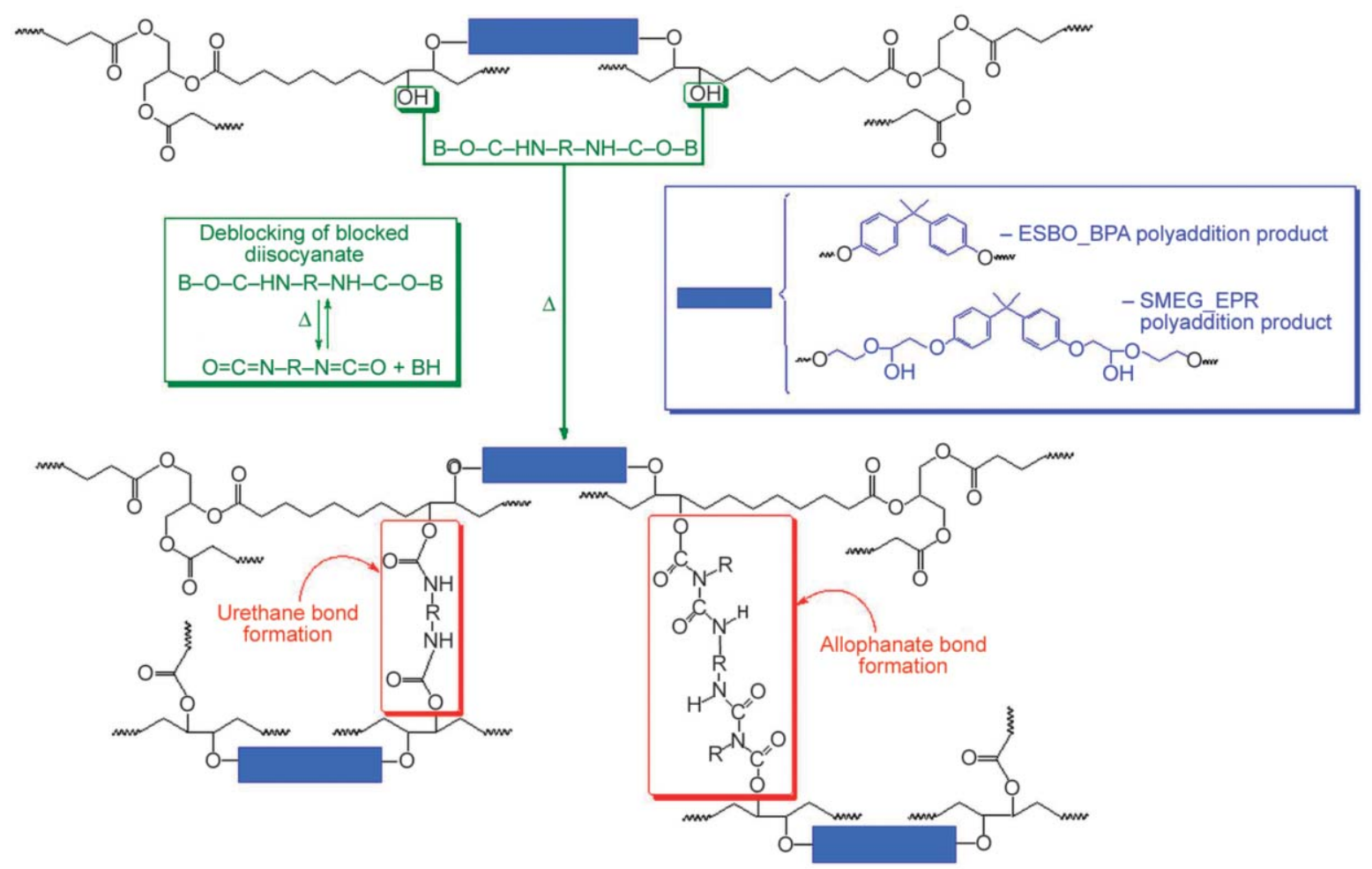

Figure 2. Curing of bio-products of polyaddition (ESBO_BPA and SMEG_EPR). 


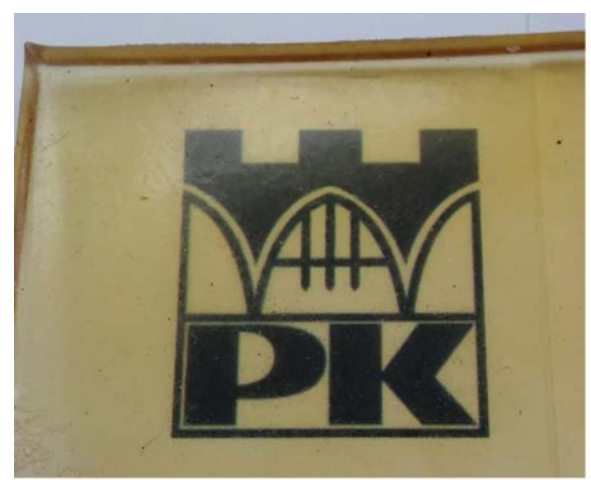

a)

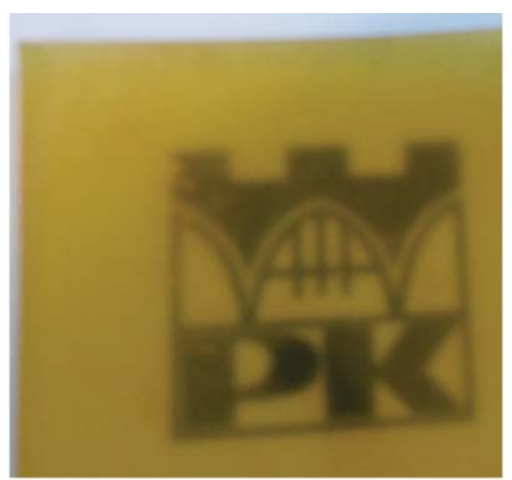

b)

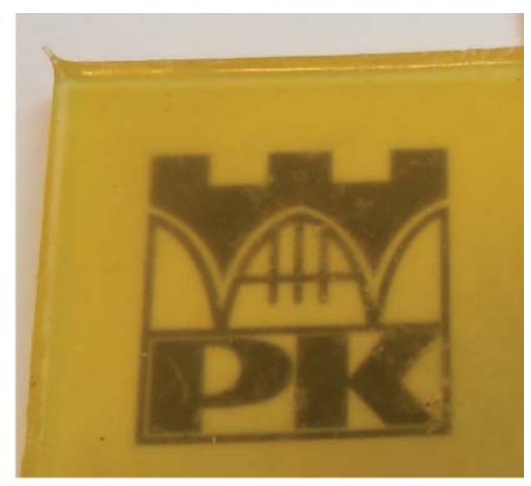

c)

Figure 3. Examples of epoxy-polyurethane compositions crosslinked using blocked isocyanates: (a) Desmocap 11, (b) D'Dur BL 3272 MPA and (c) D’Dur BL1265.

blocked isocyanates as hardeners for crossinking of polyaddition products ESBO_BPA or SMEG_EPR eliminates some of problems, which occurred for the duration of the curing using non-blocked polyisocyanates (Desmodur N75, Desmodur VL and Desmodur L75). These problems included (1) insufficient homogenization of the curing composition containing polyaddition product and hardener, due to the excessively increasing viscosity of the mixture and (2) extremely rapid curing process) [15]. All the compositions were transparent (Figure 3). Below, we present the results obtained for polyaddition products based on modified soybean oil cured with D'Dur BL1265. D'Dur BL 1265 is 65\% solution of TDI-blocked isocyanate in a mixture of 1-methoxypropyl acetate and xylene (1:1). - NCO groups $(4.8 \mathrm{wt} \%)$ of the isocyanate were blocked with $\varepsilon$-caprolactam. We poured homogeneous mixture of polyaddition product (with or without selected catalyst) and hardener into metal cuvettes, deaerated them in a vacuum oven at $40^{\circ} \mathrm{C}$ and cured at $140^{\circ} \mathrm{C}$ for about $2 \mathrm{~h}$. The gradual raising of the temperature and finally curing in $140^{\circ} \mathrm{C}$ for $2 \mathrm{~h}$ allowed for the proper degassing of prepared composition and obtaining the final product without air bubbles. In the next stage, the obtained rectangular samples of cured material were cut into paddles and subjected to mechanical tests (Figure 4). It is worth to highlight here, that the results obtained via the mechanical tests are compatible with the structural analysis of the polyaddition products based on modified soybean oil (Table 2), which were subjected to the crosslinking process. Determined properties such $\bar{M}_{\mathrm{n}}$ and $\bar{M}_{\mathrm{w}}$ are mutually complementary with the mechanical characteristic of cured material. Higher values of number average molecular weight and weight average molecular
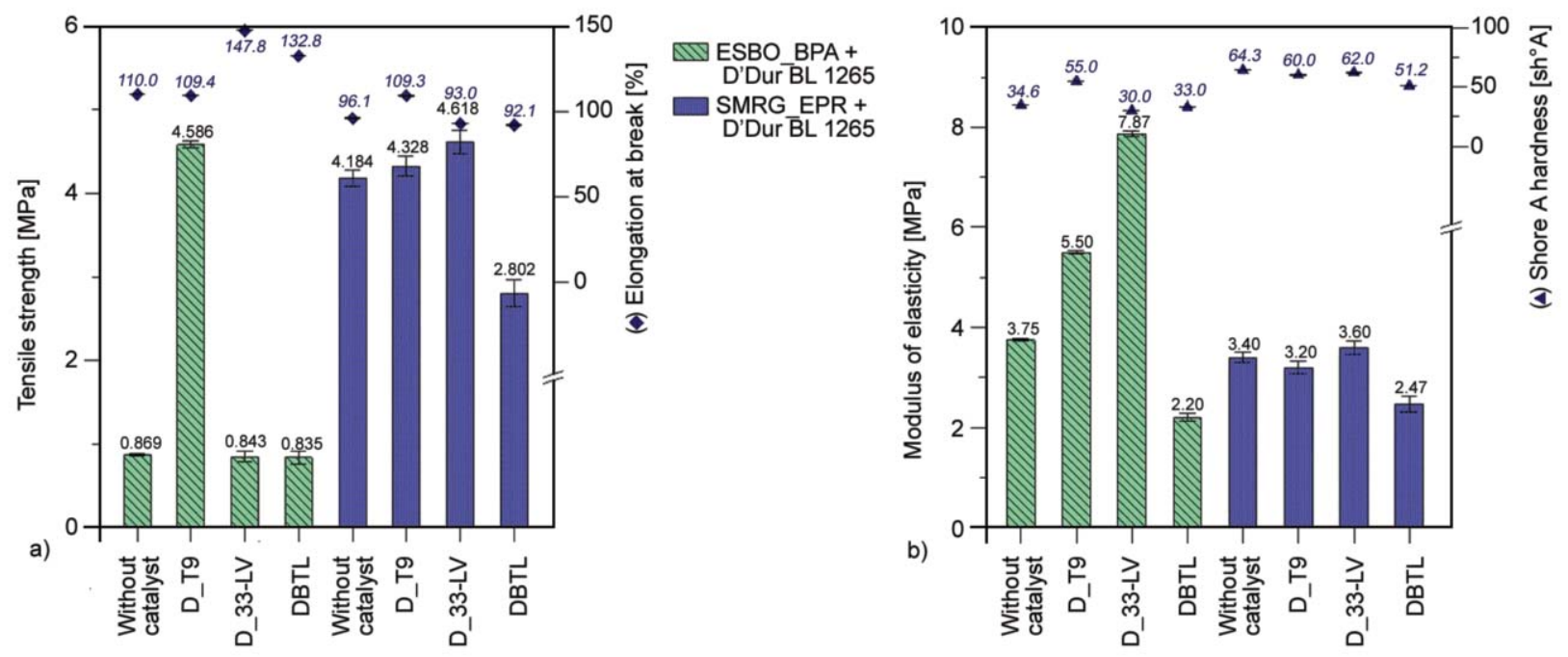

Figure 4. Mechanical properties of the ESBO_BPA and SMEG_EPR compositions crosslinked with the blocked D'Dur BL 1265 isocyanate as a hardener: (a) tensile strength and elongation at break, (b) modulus of elasticity and Shore A hardness 
weight result in higher values of tensile strength and Shore A hardness (alike in case of cured compositions based on SMEG_EPR). In turn, lower values of $\bar{M}_{\mathrm{w}}$ state about shorter molecular chains in analyzed product and at the same time higher values of elasticity and modulus of elasticity (alike in the case of compositions based on ESBO BPA).

Cured compositions of ESBO_BPA and SMEG_EPR are characterized by the hardness of 30-64 in the Shore A scale, which is of comparable or lower value than polyurethane elastomers (50-90 Shore A hardness [24, 25]). At the same time the hardest materials were obtained using polyaddition products of hydroxylated soybean oil with EPR 0162. Additionally, it was found that the use of the catalyst stannous octoate (ESBO_BPA+D'Dur BL 1265+D_T9) contributed to the composition characterized by the highest tensile strength $(4.586 \mathrm{MPa}$ compared to 0.869 MPa for compositions ESBO_BPA+D'Dur BL 1265 without catalyst) with only a slight decrease of the tensile elongation (respectively: $109.4 \%$ for ESBO_BPA+D'Dur BL 1265+D_T9 and $110.0 \%$ for ESBO BPA+D'Dur BL 1265) and an increase in values of tensile modulus by $2.25 \mathrm{MPa}$ (from respectively: $3.75 \mathrm{MPa}$ for compositions without catalyst up to 5.50 MPa for ESBO_BPA+D'Dur BL 1265+ D_T9). Consequently, when using triethylene diamine and dibutyltin dilaurate catalysts, a slight decrease of tensile strength was observed (respectively: $0.843 \mathrm{MPa}$ - D'Dur BL 1265/D_33-LV and $0.835 \mathrm{MPa}$ - D'Dur BL 1265/DBTL). Furthermore, it was also observed that products were characterized by approximately 30 and $20 \%$ increase of elongation, compared to the composition without a catalyst (147.8\% - D'Dur BL 1265/D_33-LV and 132.8\%D'Dur BL 1265/DBTL respectively). In the case of the composition cured in the presence of triethylene diamine, the Young's modulus was increased by $4 \mathrm{MPa}$, while for the composition obtained in the presence of dibutyltin dilaurate much lower value of the tensile modulus was recorded compared to the composition without a catalyst $(2.2 \mathrm{MPa}$ for ESBO_BPA+D'Dur BL 1265+DBTL and $3.75 \mathrm{MPa}$ for compositions without a catalyst). The difference in the mechanical properties of the obtained epoxypolyurethane compositions probably resulted from a different type of applied catalysts. Triethylene diamine (Dabco 33-LV), as amine catalyst with high electron donor number $(D N=50.7)$, does not affect the concentration of isocyanate/alcohol complex, but leads to a strong solvation effect, while the reaction in the presence of stannous octoate or dibutiltin dilaureate (Dabco T9 or DBTL) - as metal-based catalyst has a different mechanism, which involves $\mathrm{N}$-coordination of the isocyanate with the newly formed tin alkoxide [18].

In the case of cross-linking of the SMEG EPR product, the use of both the stannous octoate and triethylene diamine catalysts contributed to the increase of the tensile strength value. The most effective in this aspect was triethylene diamine $(4.3 \mathrm{MPa}-$ SMEG_EPR+D'Dur BL 1265+D_T9 and 4.6 MPa for SMEG_EPR+D'Dur BL 1265+D_33 LV). The observed phenomenon is likely to be related to a much less rapid course of the crosslinking process in the case of curing the composition in the presence of D_33-LV. The mechanism of the catalytic action of triethylene diamine is complex. As the amine catalyst, it acts slower and accelerates the reaction of urethane bond formation to a greater extent. Amine catalyst activity strongly depends on the donor number, and thus its small amount does not affect the concentration of $\mathrm{NCO} / \mathrm{OH}$ complex, however, leads to a solvation effect [18]. Comparing the material properties within a given polyaddition product, it was found that the cured product based on hydroxylated soybean oil crosslinked in the presence of dibutiltin dilaureate, similarly as a crosslinked polyaddition product based on epoxidized soybean oil, is characterized by the worst mechanical properties (SMEG EPR+D'Dur BL 1265+DBTL: tensile strength $-2.802 \mathrm{MPa}$, elongation $-92 \%, 2.47 \mathrm{MPa}$ - tensile modulus and a hardness of 51 Shore A compared with $4.184 \mathrm{MPa}, 91 \%, 3.40 \mathrm{MPa}$ and 64 Shore A for the composition SMEG_EPR+D'Dur BL 1265 without catalyst).

In the thermal stability test (Figure 5 and Table 3 ), thermogravimetric methods were applied to compositions which were crosslinked with D'Dur BL 1265, both without the catalyst (ESBO_BPA+D'Dur BL 1265 and SMEG_EPR+D'Dur BL 1265) and materials cured in the presence of the catalyst, for which the greatest increase in tensile strength was recorded (ESBO_BPA+D'Dur BL 1265+D_T9 and SMEG_EPR+D'Dur BL 1265+D_33-LV). Materials obtained as a result of crosslinking of the ESBO_BPA and SMEG EPR polyaddition products with the blocked D'Dur BL 1265 isocyanate show a twostage course of thermal degradation. In general, comparing thermal behavior of tested compositions, the 

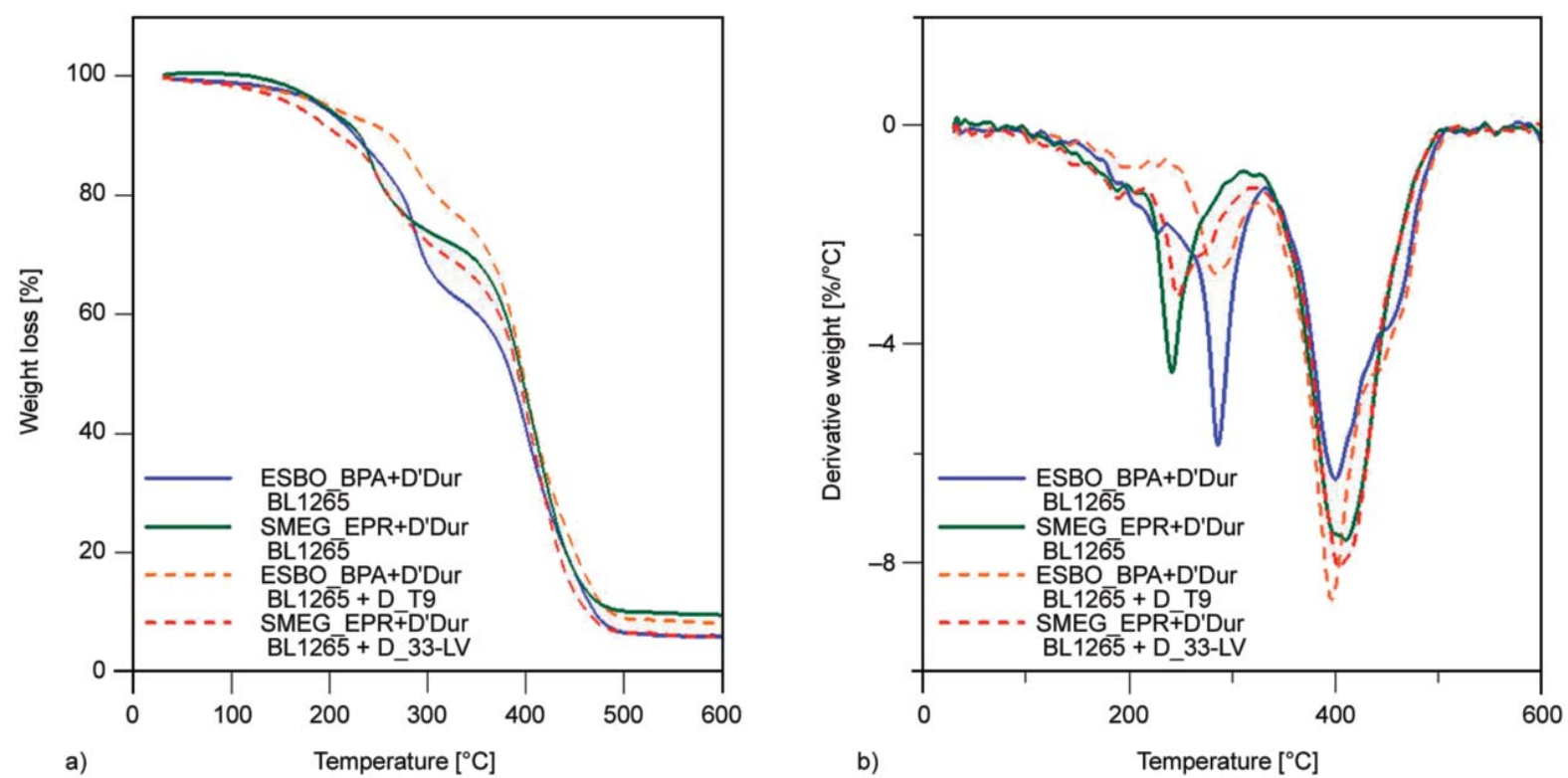

Figure 5. TGA and DTG analysis of crosslinked epoxy-polyurethane compositions: (a) TGA and (b) DTG.

Table 3. Thermal stability of the ESBO_BPA and SMEG_EPR compositions crosslinked with the blocked D'Dur BL 1265 isocyanate as a hardener.

\begin{tabular}{|c|c|c|c|c|c|c|}
\hline Composition & $\begin{array}{l}I D T_{1} \\
{\left[{ }^{\circ} \mathrm{C}\right]}\end{array}$ & $\begin{array}{c}I D T_{2} \\
{\left[{ }^{\circ} \mathrm{C}\right]}\end{array}$ & $\begin{array}{l}T_{10 \%} \\
{\left[{ }^{\circ} \mathrm{C}\right]}\end{array}$ & $\begin{array}{l}T_{20 \%} \\
{\left[{ }^{\circ} \mathrm{C}\right]}\end{array}$ & $\begin{array}{l}T_{50 \%} \\
{\left[{ }^{\circ} \mathrm{C}\right]}\end{array}$ & $\begin{array}{c}\text { Char residue } \\
{[\%]}\end{array}$ \\
\hline ESBO_BPA+D’Dur BL 1265 & 184.9 & 194.4 & 227.8 & 274.3 & 384.7 & 5.9 \\
\hline ESBO_BPA+D'Dur BL 1265+Dabco T9 & 190.8 & 200.9 & 264.8 & 308.3 & 397.2 & 8.2 \\
\hline SMEG_EPR D’Dur BL 1265 & 180.9 & 191.9 & 229.8 & 258.8 & 395.7 & 9.5 \\
\hline SMEG_EPR D'Dur BL 1265+Dabco 33-LV & 176.8 & 169.4 & 212.8 & 260.8 & 392.2 & 5.9 \\
\hline
\end{tabular}

correlation of subsequent stages of their thermal degradation (up to $T_{10 \%}$ ) was noted. Next, starting from $T_{20 \%}$ observed differences blurs. At the beginning, similarly as in the case of compositions cured using traditional isocyanates, the release of water and post-oil-modification residues of solvents occurs [15]. The first stage of thermal degradation, the cracking of urethane bonds, begins around $200^{\circ} \mathrm{C}$, and lasts until the system's temperature reaches 340 $350^{\circ} \mathrm{C}$. Urethane bonds are known to dissociate and re-associate simultaneously from around $160^{\circ} \mathrm{C}$. However, this degradation becomes irreversible from around $200^{\circ} \mathrm{C}$. Additionally, at this temperature the release of leftover traces of $\varepsilon$-caprolactam, used for -NCO blocking in applied isocyanate, may also take place. These blocking agent's residues possibly were closed in the composition during the crosslinking process, due to the rapid increase of the viscosity of the reacting system. Above $370{ }^{\circ} \mathrm{C}$, the second thermal degradation stage begins. At this temperature disintegration of ether bonds between macromolecule of modified soybean oil and bisphenol A is observed. In turn, above $400^{\circ} \mathrm{C}$, the fragments of bisphenol segments are likely to break up [28, 29].

The use of catalysts affects changes in the temperature of the beginning of subsequent stages of thermal degradation. For products cured in the presence of stannous octoate (cured composition ESBO_BPA+ D'Dur BL 1265+D_T9) we recorded the shift towards to the higher temperatures, and for the composition crosslinked in the presence of triethylene diamine (cured material SMEG_EPR+D'Dur BL $1265+\mathrm{D} 33-\mathrm{LV})$ - to the lower temperatures, compared to the corresponding composition cured without the use of a catalyst (ESBO_BPA+D'Dur BL 1265 or SMEG EPR+D'Dur BL 1265). Additional$1 \mathrm{y}$, in case of the composition cured in a presence of stannous octoate, compared to the cured product obtained without the use of a catalyst, an increase in the amount of solid residue from the process was found. A different effect was noted for the system with and without the D_33-LV catalyst.

SEM microphotographs (Figure 6) of the impact fracture surfaces of materials crosslinked with D'Dur BL 


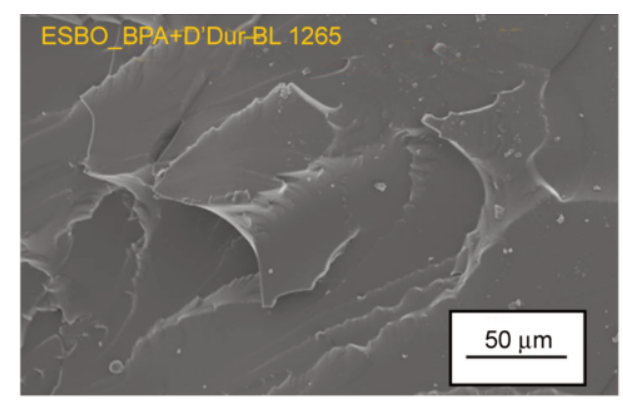

a)

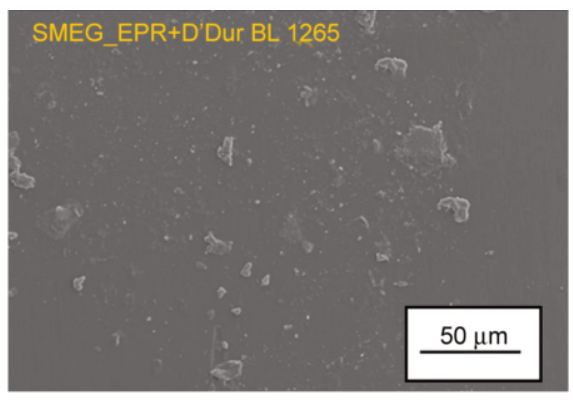

b)

Figure 6. SEM microphotographs of the impact fracture surface of the composition based on the ESBO_BPA (a) or SMEG_EPR (b) polyaddition product crosslinked with D'Dur BL 1265 as a hardener.

1265 show a homogeneous structure of obtained compositions. It was observed that both materials do not show brittle fractures that spread in different directions and are characteristic for epoxy resins. At the same time surface of material based on hydroxylated soybean oil was more uneven than the one obtained with the use of ESBO. Above observation relate closely to structural and mechanical characteristic of obtained cured compositions, which were discussed in previous paragraphs. Products obtained with the use of hydroxylated soybean oil are characterized by longer and more branched molecular chains than those synthesized with the application of epoxidized soybean oil. In other words, higher values of number average molecular weight and weight average molecular weight result in higher mechanical resistance and the same more uneven surface of impact fracture. In turn, lower values of $\bar{M}_{\mathrm{w}}$ (alike in the case of compositions based on ESBO_BPA) state about shorter molecular chains of analyzed product and at the same time higher values of elasticity and milder destruction due to impact forces.

\section{Two-layer materials}

As it was mentioned before, the polyaddition products of modified soybean oil with bisphenol A or a low molecular weight epoxy resin based on BPA contain in their macromolecules two types of functional groups (epoxide and hydroxyl) that can be use in the curing process. The research presented above was focused only on materials crosslinked by the reaction

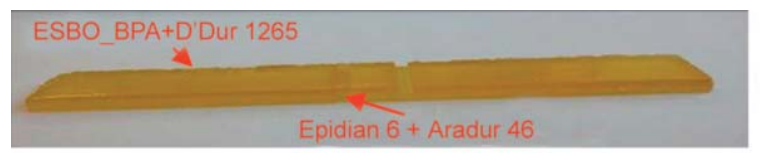

a) of hydroxyl groups (which occurs in larger amount in the system, subjected to curing) of the polyaddition product and the $-\mathrm{NCO}$ group of the hardener. However, the epoxy groups, even those characterized by the relatively lower reactivity - located centrally in the triglyceride chains - could also be used during the curing process. That is why the additional presence of free epoxy groups in polyaddition products was utilized during the preparation of doublelayer materials. These products were obtained by chemical bonding of two different compositions via the previously unused oxirane groups of the crosslinked ESBO_BPA or SMEG_EPR products. In the first stage, materials based on hydroxylated soybean oil (SMEG) or polyaddition products ESBO_BPA and SMEG_EPR were crosslinked with the use of D'Dur 1265 in accordance with the previously described procedure. Then, the homogenous mixture containing Epidian 6 and hardener Aradur 46 was poured on cured compositions: SMEG+D'Dur 1265, ESBO_BPA+D'Dur 1265 or SMEG_EPR+D'Dur 1265 (Table 4). The amount of Aradur 46 was selected taking into account the content of epoxy groups in both layers of the prepared material. Then the obtained rectangular double-layer plates were cut in accordance with ISO 4587:2003 [22]. The formed incisions were used to separate the layers of the compositions during the shear strength test of the lap joints. The individual cuts were made so that the incisions of the second layer were as small as possible. (Figure 7). In the next step, prepared samples were

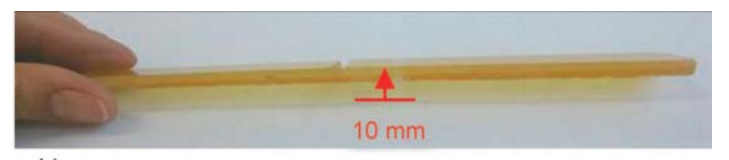

b)

Figure 7. Double-layer materials: (a) composition B, (b) incisions used to separate the layers of the compositions during the shear strength test of the lap joints. 
tested on the Zwick 1445 to determine the shear strength during stretching the overlap joints (Table 4).

Based on the results of the conducted tests, a different degree of binding of the tested double-layer materials was found. As expected, a material in which one of the layers consisted of hydroxylated soybean oil (not containing epoxy groups) crosslinked with D'Dur 1265 was characterized by the smallest value of $\tau$ strength $\left(0.04 \mathrm{~N} / \mathrm{mm}^{2}\right)$. At the same time, we recorded

Table 4. The shear strength during stretching the overlap joints of double-layer materials.

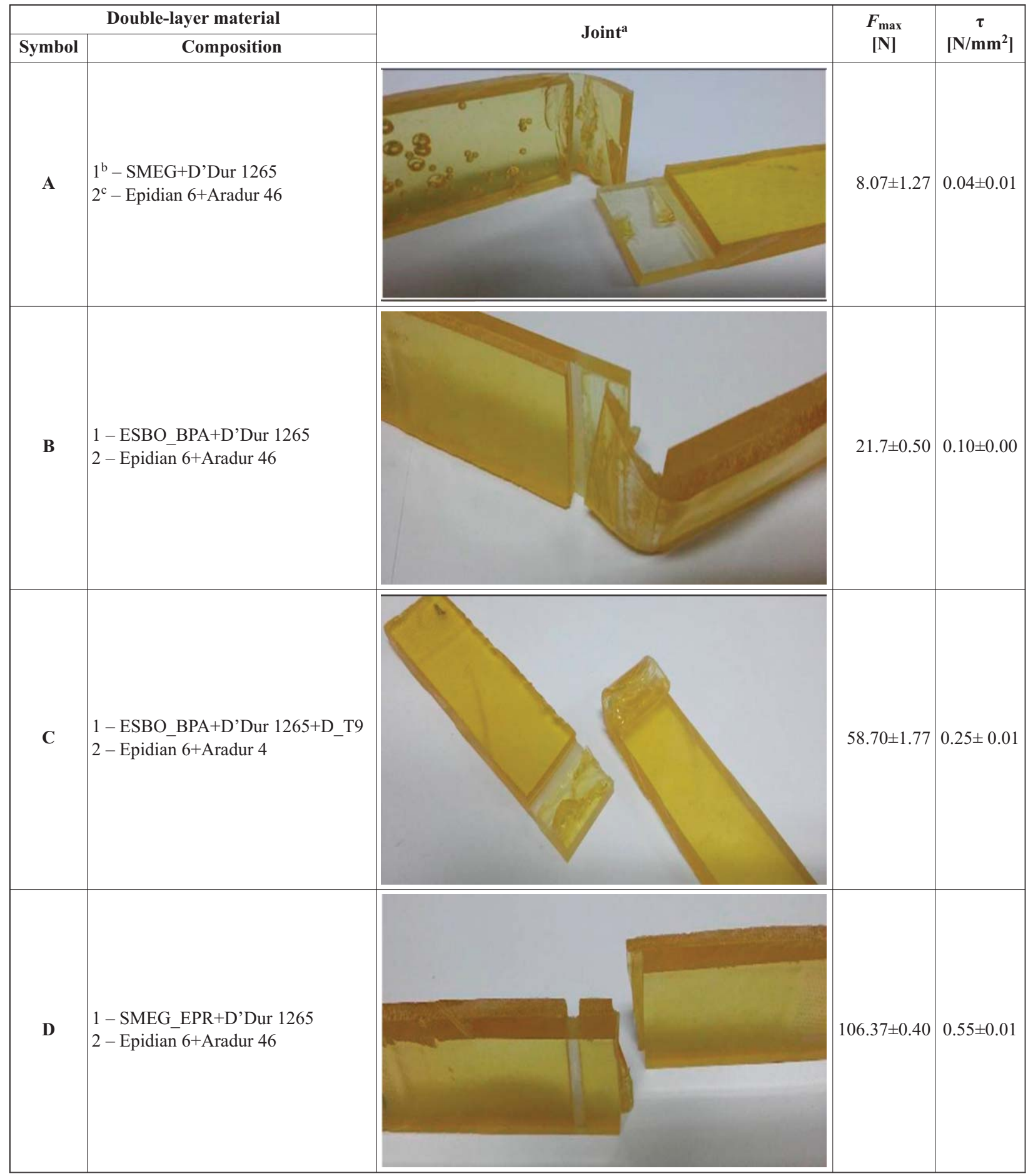

${ }^{a}$ the joint area of the double-layer materials after the shear strength test

${ }^{b} 1$ - the first layer of double-layer material formed from the composition based on polyaddition product of modified soybean oil and BPA or EPR 0162 cured with D'Dur 1265 as curing agent

c2 - second layer of double-layer material formed from the composition based on commercial epoxy resin Epidian 6 cross-linked with Aradur 46 as curing agent 
higher values of maximum applied force, and thus higher values of shear strength in the case of double-layer materials based on polyaddition products, in comparison with a double-layer material based on hydroxylated vegetable oil. Chemical bonding of layers: SMEG_EPR+D'Dur 1265 and Epidian 6 + Aradur 46 through the epoxy groups present in the polyaddition product is characterized by the highest strength among all tested materials. The significantly higher values of $\tau$ of this material, in comparison with the double-layered material based on ESBO_BPA, could have resulted from the better mechanical properties of the cured layer based on polyaddition product. The similar regularity is found in the case of two-layer materials $\mathbf{B}$ and $\mathbf{C}$ (containing the layer based on cross-linked ESBO_BPA product; $\mathbf{B}$ - the composition cured without a catalyst, $\mathbf{C}$ - with stannous octoate). For sample $\mathbf{C}$, the values of $\tau$ strength were higher than for material $\mathbf{B}$. Bio-composition of $\mathbf{B}$ and $\mathbf{C}$ two-layered materials also differed in their mechanical properties. The composition ESBO_BPA+D'Dur 1265+D_T9 (used as one of the constituents of the $\mathbf{C}$ material) was characterized by a 4 times higher tensile strength with only slightly lower breaking strength compared to the composition ESBO_BPA+D'Dur 1265 (used as a component of material $\mathbf{B}$ ).

The analysis of SEM microphotographs of the postsheer stress surface of samples $\mathbf{B}$ and $\mathbf{D}$ materials (Figure 8) clearly shows two layers: first one, characteristic for epoxy resin based on petrochemical raw materials, with sharp-edged surfaces (Epidian $6+$ Aradur 46) and the second one with milder jagged fragments characteristic of fracture surfaces of a cured material of polyaddition products based on modified vegetable oil and BPA or EPR 0162 (ESBO_BPA+D'Dur 1265+D_T9 or SMEG_EPR+ D'Dur 1265) [15, 23]. Additionally, in the case of materials containing the ESBO_BPA polyaddition product, the gradual separation of the two layers is clearly visible. For the one with SMEG_EPR, the layers closely adhere to each other, and damage occurred during the shear test are visible within individual layers and in the joint area. The free oxirane groups, which are still present in the cured (by the reaction of hydroxyl groups of the polyaddition product with the isocyanine groups of the hardener) composition, can be successfully used for the chemically binding another layer of new composition. It is worth to highlight that a multi-layer material, which is characterized by the mechanical properties closely related to the individual constituent compositions can potentially be obtained using above described procedure.

\section{Conclusions}

Polyaddition products ESBO_BPA and SMEG_EPR, obtained via the epoxy fusion process, contain both epoxy and hydroxyl functional groups, which are suitable for the curing purposes. Crosslinked throughout $-\mathrm{OH}$ groups is possible using isocyanates. The type of an isocyanate hardener determines the properties of epoxy-polyurethane materials. Application of blocked isocyanates is not only more ecological, but also eliminates some of problems encountered during the curing with Desmodur N75, Desmodur VL and Desmodur L75 polyisocyanates (such as e.g.:

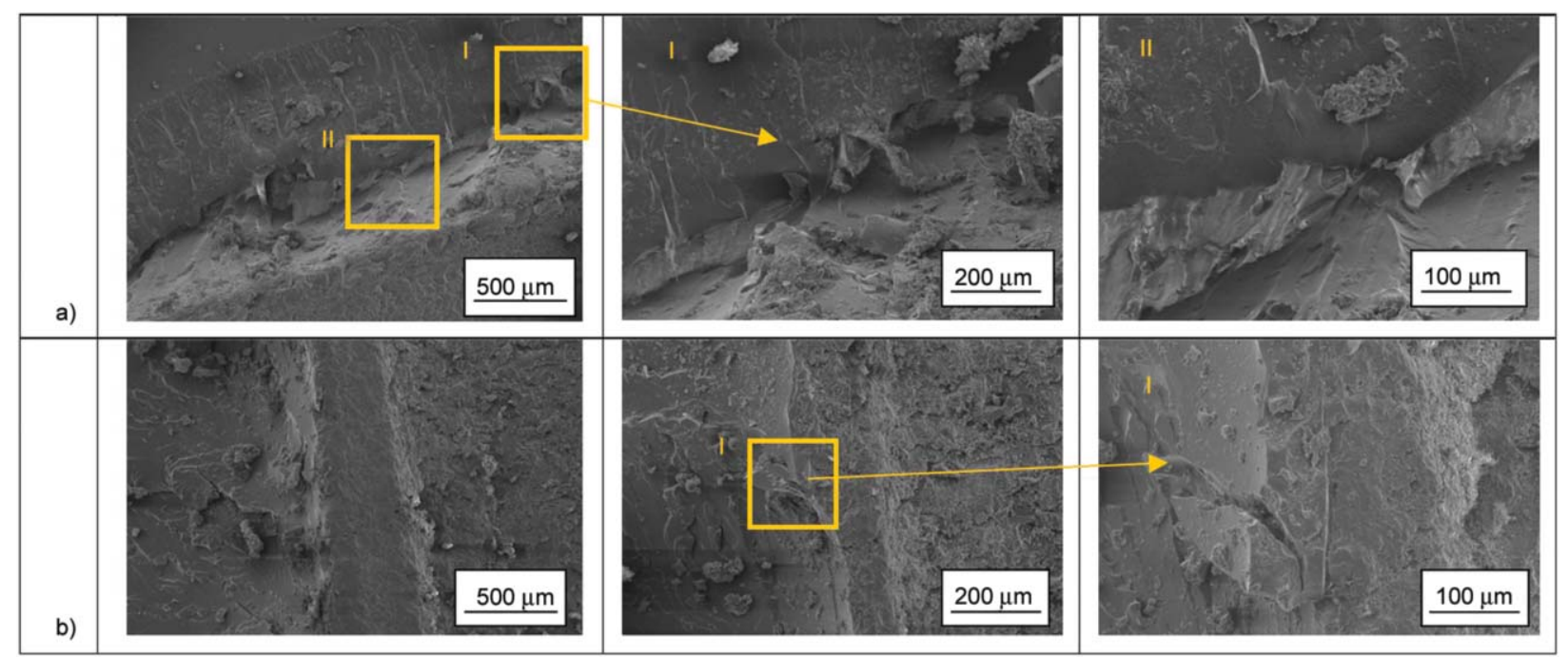

Figure 8. SEM photomicrographs of the combination surface of the composition in two-layer materials: (a) composition C, (b) composition $\mathbf{D}$. 
(1) insufficient homogenization of the curing composition containing polyaddition product and hardener, due to the excessively increasing viscosity of the mixture or (2) extremely rapid curing process) [15]. Based on performed studies it was found that crosslinking of the polyaddition product with the use of D'Dur BL 1265 in the presence of stannous octoate or triethylene diamine as catalysts: gives a material with better mechanical properties compared to the composition crosslinked without the use of the catalyst. Additionally, obtained materials might be cured 1) individually - through - $\mathrm{OH}$ groups, using hardeners based on various isocyanates, as well as by 2) less active oxirane groups in connection with other epoxy materials to form multilayer materials, which possibly might be used in the civil and material science engineering. Based on performed experiments, it has been found that oxirane groups, which are present in the obtained polyaddition products might successfully be use to connect these materials to form multilayer products. Such multilayer materials are applied as construction materials and are very interesting due to the ability of preservation of properties, typical for the individual layer.

\section{References}

[1] Ciesielski S., Mozejko J., Pisutpaisal N.: Plant oils as promising substrates for polyhydroxyalkanoates production. Journal of Cleaner Production, 106, 408-421 (2015).

https://doi.org/10.1016/j.jclepro.2014.09.040

[2] Mahapatra S. S., Karak N.: Synthesis and characterization of polyesteramide resins from Nahar seed oil for surface coating applications. Progress in Organic Coatings, 51, 103-108 (2004).

https://doi.org/10.1016/j.porgcoat.2004.07.003

[3] Akintayo C. O., Akintayo E. T., Ziegler T.: Studies on newly developed urethane modified polyetheramide coatings from Albizia benth oil. Progress in Organic Coatings, 71, 89-97 (2011).

https://doi.org/10.1016/j.porgcoat.2011.01.003

[4] Saravari O., Phapant P., Pimpan V.: Synthesis of waterreducible acrylic-alkyd resins based on modified palm oil. Journal of Applied Polymer Science, 96, 1170-1175 (2005). https://doi.org/10.1002/app.21009

[5] Zhang C., Garrison T. F., Madbouly S. A., Kessler M. R.: Recent advances in vegetable oil-based polymers and their composites. Progress in Polymer Science, 71, 91-143 (2017).

https://doi.org/10.1016/j.progpolymsci.2016.12.009
[6] Sharmin E., Zafar F., Akram D., Alam M., Ahmad S.: Recent advances in vegetable oils based environment friendly coatings: A review. Industrial Crops and Products, 76, 215-229 (2015).

https://doi.org/10.1016/j.indcrop.2015.06.022

[7] Nguyen T. K. L., Livi S., Soares B. G., Barra G. M., Gérard J-F., Duchet-Rumeau J.: Development of sustainable thermosets from cardanol-based epoxy prepolymer and ionic liquids. ACS Sustainable Chemistry \& Engineering, 5, 8429-8438 (2017).

https://doi.org/10.1021/acssuschemeng.7b02292

[8] Teacă C-A., Roşu D., Tanasă F., Zănoagă M., Mustaţă F.: Epoxidized vegetable oils for thermosetting resins and their potential applications. in 'Functional biopolymers' (eds.: Thakur V., Thakur M.) Springer, Cham, 217-238 (2018).

https://doi.org/10.1007/978-3-319-66417-0 8

[9] Fernandes F. C., Kirwan K., Lehane D., Coles S. R.: Epoxy resin blends and composites from waste vegetable oil. European Polymer Journal, 89, 449-460 (2017).

https://doi.org/10.1016/j.eurpolymj.2017.02.005

[10] Nikafshar S., Zabihi O., Hamidi S., Moradi Y., Barzegar S., Ahmadi M., Naebe M.: A renewable bio-based epoxy resin with improved mechanical performance that can compete with DGEBA. RSC Advances, 7, 8694-8701 (2017).

https://doi.org/10.1039/C6RA27283E

[11] Stemmelen M., Lapinte V., Habas J-P., Robin J-J.: Plant oil-based epoxy resins from fatty diamines and epoxidized vegetable oil. European Polymer Journal, 68, 536-545 (2015). https://doi.org/10.1016/j.eurpolymj.2015.03.062

[12] Czub P.: Characterization of an epoxy resin modified with natural oil-based reactive diluents. Macromolecular Symposia, 245-246, 533-538 (2006). https://doi.org/10.1002/masy.200651377

[13] Czub P., Kasza P.: Study on mechanical properties of the crosslinked with isocyanates product of the reaction of modified soybean oil with epoxy resin. Polimery, 59, 466-476 (2014). https://doi.org/10.14314/polimery.2014.466

[14] Czub P.: Application of modified natural oils as reactive diluents for epoxy resins. Macromolecular Symposia, 242, 60-64 (2006). https://doi.org/10.1002/masy.200651010

[15] Sienkiewicz A., Czub P.: Novel bio-based epoxypolyurethane materials from modified vegetable oils Synthesis and characterization. Express Polymer Letters, 11, 308-319 (2017). https://doi.org/10.3144/expresspolymlett.2017.30

[16] Sienkiewicz A., Czub P.: Synthesis of high-molecular weight biobased epoxy resins: Determination of the course of the process by MALDI-TOF mass spectrometry. ACS Sustainable Chemistry and Engineering, 6, 6084-6093 (2018). https://doi.org/10.1021/acssuschemeng.7b04727 
[17] Pilch-Pitera B., Byczyński Ł.: Study on the thermal behavior of new blocked polyisocyanates for polyurethane powder coatings. Progress in Organic Coatings, 101, 240-244 (2016). https://doi.org/10.1016/j.porgcoat.2016.08.013

[18] Delebecq E., Pascault J-P., Boutevin B., Ganachaud F.: On the versatility of urethane/urea bonds: Reversibility, blocked isocyanate, and non-isocyanate polyurethane. Chemical Reviews, 113, 80-118 (2012). https://doi.org/10.1021/cr300195n

[19] Tassel X., Barbry D., Tighzert L.: A new blocking agent of isocyanates. European Polymer Journal, 36, 17451751 (2000).

https://doi.org/10.1016/S0014-3057(99)00271-2

[20] Czub P.: Synthesis of high molecular weight epoxy resins from modified natural oils and Bisphenol A or Bisphenol A-based epoxy resins. Polymers for Advanced Technologies, 20, 194-208 (2009).

https://doi.org/10.1002/pat.1252

[21] Subramani S., Park Y-J., Lee Y-S., Kim J-H.: New development of polyurethane dispersion derived from blocked aromatic diisocyanate. Progress in Organic Coatings, 48, 71-79 (2003).

https://doi.org/10.1016/S0300-9440(03)00118-8

[22] ISO 4587:2003 - Standard method: Adhesives - Determination of tensile lap-shear strength of rigid to rigid bonded assemblies.

[23] Sienkiewicz A., Czub P.: Synthesis and mechanical properties of novel epoxy-polyurethane materials based on modified soybean oil. 2016, Chemistry, 1Ch/2016, 111-123 (2016).

https://doi.org/10.4467/2353737XCT.16.052.5314
[24] Yeganeh H., Mehdizadeh M. R.: Synthesis and properties of isocyanate curable millable polyurethane elastomers based on castor oil as a renewable resource polyol. European Polymer Journal, 40, 1233-1238 (2004). https://doi.org/10.1016/j.eurpolymj.2003.12.013

[25] Fink I., Eling B., Pöselt E., Luinstra G. A.: Polyurethane elastomers based on amphiphilic poly(caprolactone)- $b$-poly(butadiene)- $b$-poly(caprolactone) triblockcopolyols. Journal of Polymer Science Part A: Polymer Chemistry, 56, 1162-1172 (2018).

https://doi.org/10.1002/pola.29001

[26] Sienkiewicz A., Czub P.: Application of MALDI-TOF, ${ }^{1} \mathrm{H}$ NMR and ${ }^{13} \mathrm{C}$ NMR to follow the progress of the synthesis of high molecular weight epoxies from hydroxylated soybean oil and bisphenol A based epoxy resin. Polymer Testing, 73, 200-207 (2019).

https://doi.org/10.1016/j.polymertesting.2018.11.015

[27] Randall D., Lee S. The polyurethanes book. Wiley, New York (2002).

[28] Gerbase A. E., Petzhold C. L., Costa A. P. O.: Dynamic mechanical and thermal behavior of epoxy resins based on soybean oil. Journal of the American Oil Chemists' Society, 79, 797-802 (2002). https://doi.org/10.1007/s11746-002-0561-z

[29] Hablot E., Zheng D., Bouquey M., Avérous L.: Polyurethanes based on castor oil: Kinetics, chemical, mechanical and thermal properties. Macromolecular Materials and Engineering, 293, 922-929 (2008). https://doi.org/10.1002/mame.200800185 